\title{
The Use Of Physical Restraint: An Argumentative Essay
}

\author{
Rami Abdeljawad, RN., M.SC
}

Hashemite University, Jordan

Majd T. Mrayyan

Consultant of Nursing, The Hashemite University, Jordan

\section{doi: 10.19044/esj.2016.v12n9p433 URL:http://dx.doi.org/10.19044/esj.2016.v12n9p433}

\begin{abstract}
This study was conducted to review the literature about the use of physical restraints as an argumentative issue. The use of physical restraints has been reported with varying prevalence from $41 \%$ to $64 \%$ according to epidemiological studies. In this study, the author reviewed the opinions of the opponent and proponent viewpoints regarding physical restraints from legal and ethical perspectives. The ideas of proponents implied that the use of physical restraints offers protection for patients and others as well as ensures introducing good treatment. On the other hand, the opponents think that the use of physical restraints is not well safe and associated with legal and ethical issues. Furthermore, psychological injuries and mental problems have been reported to be associated with the use of physical restraints. The author agrees with the opponents and does not support the use of physical restraints because it involves ethical, legal and health impacts.
\end{abstract}

Keywords: Physical restraints, opponents, proponents, ethical point of views, legal point of views

\section{Introduction}

The ethical dimension of care is an essential part of good nursing practice, and ethical reflection is necessary for nurses to come to thoughtful and balanced decisions. Critical reflection on what constitutes good care is required in everyday care, but even more so in ethically charged situations such as those requiring physical restraint (Goethals, Casterle, and Gastmans, 2012).

A physical restraint is defined as a device which can be applied directly or indirectly to control or immobilize an individual (Mullaney, Pettersson, Nyholm, and Stolterman, 2012). The criteria of mechanical 
restraints included side-rails, table-tops, bedclothes, tipping chairs, wheelchair belt when not in transit (Bergk, et al., 2015).

According to the study of Michael et al (2006), the use of physical restraint to manage behavior is controversial. The definition of physical restraints implies the use of any manual means or physical or mechanical device, material, or equipment attached or adjacent to the patient's body to impede or restrict freedom of movement or normal access to one's body (United States General Accounting Office, 1999).

An argumentative essay is a style of writing that need to investigate a topic; gather, generate, and evaluate evidence; and establish a position on a controversial issue in a concise manner, and you try to clarify some points and present evidence in favor of your position (Wingate, 2012). The use of physical restraints, however, is still a common practice (with a prevalence of 33-68\%) in acute care settings (Goethals, Dierckx, and Gastmans, 2012). Therefore the purpose of this argumentative essay paper is to articulate the opponents and proponents viewpoints regarding physical restraints from legal and ethical perspectives.

\section{Background}

Physical restraint is one of the most issues that nurses phases in their daily practice, not realizing that physical restraint is one of the most depleting ethical argument in health care facilities, as well as in home care services. The purpose of this literature review is to draw out the opponents and proponents viewpoints regarding the physical restraints from legal and ethical perspectives.

The use physical restraints has been reported globally in nursing homes with a varying rates from $41 \%$ and 66\% (Hamers and Huizing, 2005). Theprevalence of using physical restraints in Western Australia was 26\% (Retsas, 1997), Queensland 24\% (Retsas and Crabbe, 1997) and New South Wales 15\% (Retsas and Crabbe, 1998).

\section{Legal and Ethical Opponents of the Use of Physical Restraints}

Some authors expressed their own views that the perception of children for physical restraints as aggressive and punitive which may influence the effective treatment (Fox, 2004). The severe risks of using physical restraints such as severe physical and psychological injury and death have been argued through several studies particularly when used for children (Busch and Shore, 2010).

It has been indicated that the bad experience resulting from repeated the procedures of physical restraints may approximate that induced by cancer such as being painful, traumatic and anxiety (Magee, 2014). Other studies indicated that irrespective to the consideration that the use of physical 
restraints offers a quick fix solution, its use may cause physical and psychological suffering (Morris and Taub,2010). Furthermore, Mattiasson and Andersson (1995) showed that the use of physical restraints forms a violation of the patient's freedom and autonomy. According to this context, suggestions have implied that the use of physical restraints and the control and manipulation of behavior are considered from ethical point of view as highly doubtful solutions (Bandman and Bandman, 1990; Tschudin, 2003). Evans et al (2003) put emphasis on the consideration that physical restraints do not ensure safety. Other reports showed that the use of physical restraints may increase patient agitation and lead to significant side effects such as serious injury and even death (Evans et al., 2003; Knox and Holloman, 2012). It has been estimated that about 100 deathstake place annually (in the USA) resulting from improper use of physical restraints (Azab and Abu Negm, 2013).

\section{Legal and Ethical Proponents of the Use of Physical Restraints}

There are several proponents for the use of physical restraints including obtaining some therapeutic benefits through encouraging coping skills and internal means of self-control (Ahn, 2011).

The use of physical restraints has been argued from medical, legal, and psychological perspectives and its relative benefits and risks lead to questions about its legality, and its effectiveness on extinguishing or modifying aggressive and violent behavior (Peay, 2011).

Up to $80 \%$ of patients in ICU may experience some degree of agitation, confusion and delirium during their Stay, caused by pain, underlying illness, sleep deprivation, hypoxia, mechanical ventilation, myocardial ischemia, alcohol and substance withdrawal and altered cell metabolism, as a result, Patients may attempt to remove invasive devices, therefore Physical and chemical restraints may be used to address the problem (Langley, Schmollgruber and Egan, 2011).

Emphasizing that fact, in a study held in Netherlands, in order to evaluate the prevalence of restraining among RN working in home care, the results indicates that; four of every five nursing staff members have applied physical restraints. The use of bed rails, putting the client in a deep chair or using a chair with a table, and locking doors to prevent wandering were most frequently applied, which is something should be evaluated critically (Bader, 2013).

In a summary, the purpose of this literature review was to draw out the opponent and proponent viewpoints with regard to the use of physical restraints from ethical and legal perspectives. The ideas of proponents implied that the use of physical restraints offers protection for patients and others as well as ensures introducing good treatment. On the other hand, the 
opponents think that the use of physical restraints is not well safe and associated with legal and ethical issues. Furthermore, psychological injuries and mental problems have been reported to be associated with the use of physical restraints.

\section{Argumentative Statement}

In view of previous context in which the use of physical restraints was discussed in details, the author is against the use of physical restraints. Although the use of physical restraints seems to offer practical therapeutic solutions for patients, its use, as shown before, does not ensure safety and several injuries and fatalities have been associated with the use physical restraints. Furthermore, the use of physical restrains raise ethical and legal aspects. Controlling the behavior of others by force leads to psychological injuries with bad outcomes, particularly among those with previous bad experience. It is also not ethical and not legal to impede the freedom of others.

Therefore, the current author articulates the following course of actions and recommendations to control and regulate the physical restraints:

1. If the physical restraints will be used, it is recommended to ensure firstly that it is the last option.

2. Consent forms have to be filled by the patient or his family before the use of physical restraints because of the involvement of ethical issues.

3. Once the physical restraints is used, the nurse should monitor the patient periodically to ensure the fine going of interventional process.

4. Although the use of restraints can be seen as a quick fix solution to this behaviour, there is ample evidence that restraint use causes both physical and psychological suffering.

5. Education should include more knowledge about what physical restraints are, the consequences of restraint use, and the range of possibilities for meeting elderly people's needs, including needs for safety, also nursing education must focus on determining risk factors for injury and on how to create a safe environment.

The current author asserts that the use of physical restraints in the clinical practice is not permissible and must be prohibited.

\section{Summary and Conclusion}

The use of physical restraints is still an argumentative issue and in daily nursing practice, nurses face this situation. Although the use of physical restraints purposes to prevent injuries and harms to the patient and others, there is a possibility that patients under the physical restraints will be exposed to injuries and even death. Furthermore, the use of physical 
restraints has been associated with legal and ethical aspects. The author does not support the idea of using physical restraints.

\section{References:}

Ahn, Y. (2011). Behavioral Intervention Programs As an Alternative to Mechanical Restraints: Cost-Benefit Analysis and Policy Recommendations.S. Cal. Rev. L. and Soc. Just., 21, 21.

Azab, S., Abu Negm, L. (2013). Use of Physical Restraint in Intensice care Units (ICUs) at Ain Shams University Hospitals, Cairo. Journal of American Science, 9(4), 230-240.

Bader, K. W. (2013). Argumentative Essay; Restraints. Restraints (April 17, 2013).

Bandman, E., Bandman, B., 1990. Nursing Ethics Through theLife Span. Practice Hall, New York.

Bergk, J., Einsiedler, B., Flammer, E., Steinert, T. (2015). A randomized controlled comparison of seclusion and mechanical restraint in inpatient settings. Psychiatric Services.

Busch, A. B., Shore, M. F. (2010). Seclusion and restraint: A review of recent literature. Harvard review of psychiatry.

Evans D, Wood J, Lambert L. (2003). Patient injury and physical restraint devices: a systematic review. J AdvNurs, 41(3):274-82.

Fox, L. (2004). The impact of restraint on sexually abused children and youth. Residential Group Care Quarterly, 4 (3), 1-5.

Goethals S. a, Casterle B. Dierckx de ' b, C. Gastmans. (2012). Nurses' decision-making process in cases of physical restraint in acute elderly care: A qualitative study, International Journal of Nursing Studies, NS-2109, 10.

Goethals, S., Dierckx de Casterlé, B., Gastmans, C. (2012). Nurses' decision-making in cases of physical restraint: a synthesis of qualitative evidence. Journal of advanced nursing, 68(6), 1198-1210.

Hamers JPH, Huizing AR. (2005). Why do we use physical restraints in the elderly? Z GerontolGeriatr, 38:19-25.

Knox, D. K., Holloman, G. H. (2012). Use and avoidance of seclusion and restraint: consensus statement of the American association for emergency psychiatry project Beta seclusion and restraint workgroup. Western Journal of Emergency Medicine, 13(1).

Langley Gayle, Schmollgruber Shelley, Egan Anthony. (2011). Restraints in intensive care units-A mixed method study, Intensive and Critical Care Nursing, 27, 67-75.

Magee, D. J. (2014). Orthopedic physical assessment. Elsevier Health Sciences. 
Mattiasson, A., Andersson, L., (1995). Nursing home staff attitudes to ethical conflicts with respect to patient autonomy and paternalism. Nursing Ethics 2 (2), 115-130.

Michael A. Nunno, Martha J. Holden, Amanda Tollar, (2006). Learning from tragedy: A survey of child and adolescent restraint fatalities. Child Abuse and Neglect 30, 1333-1342.

Morris, D., andTaub, E. D. W. A. R. D. (2010). Constraint-induced movement therapy. Improving functional outcome in physical rehabilitation, 232-245.

Mullaney, T., Pettersson, H., Nyholm, T., andStolterman, E. (2012). Thinking beyond the cure: A case for human-centered design in cancer care. International Journal of Design, 6(3).

Peay, J. (2011). Personality disorder and the law: Some awkward questions.Philosophy, Psychiatry, and Psychology, 18(3), 231-244.

Retsas, A (1997). The use of physical restraints in Western Australian nursing homes. Australian Journal of Advanced Nursing 14 (3), 33-39.

Retsas, A., Crabbe, H. (1997). Breaking loose: use of physical restraints in nursing homes in Queensland. Australia Collegian 4 (4), 14-21.

Retsas, A., Crabbe, H (1998). Use of physical restraints in nursing homes in New South Wales, Australia. International Journal of Nursing Studies 35 (3), 177-183.

Tschudin, V (2003). Ethics in Nursing: The Caring Relationship, third ed. Butterworth Heinemann, Oxford.

United States General Accounting Office (1999). Mental health: Improper restraint or seclusion places people at risk. Washington, DC: United States General Accounting Office. GAO/HEHS-99-176.

Wingate, U. (2012). Argument!'helping students understand what essay writing is about. Journal of English for Academic Purposes, 11(2), 145-154. 